\title{
Sources of Prevailing Differences in Unemployment Rates For Selected Regional Pairs
}

\section{Lou Pantuosco and Darrell Parker*}

\begin{abstract}
This paper provides a focused examination of state fiscal policies on labor supply. To compare unemployment rates, four U.S. states and one U.S. region were matched with neighboring twins that exhibit similar labor demand relationships. In each case, a difference in unemployment rates has persisted since the early 1970 s. The impact of state fiscal policies on unemployment insurance and public assistance on the differences in unemployment rates is estimated. Both fiscal packages contribute to the unemployment difference for some states.
\end{abstract}

\section{INTRODUCTION}

One of the most spirited debates in economic discussion has been unemployment and its causes. In particular, there is a mystique regarding unemployment rates. National, state, and local unemployment rates vary over time and across areas. The causes for these variations have been the topic of economic debate since economic debates began (See Marston 1985; Summers 1986; Blackley 1989; Hyclak and Johnes 1992; Partridge and Rickman 1994; Shannon and Anderson 1996). If the causes of unemployment are understood, could government policy improve the status of the job seekers? On the other hand, are government policies themselves actually one of the causes for persistent variations in unemployment? An understanding of the relationship between state fiscal policies and labor supply is important within the current environment of "welfare reform" at the state level.

Analysis of these issues often has been clouded by the lack of consistency between the areas being discussed. A cross-country study of unemployment rate variation has to cope with different monetary policies and possibly different measurement methodologies. An analysis of regions or states within the same country may face different industrial make-ups and regional shocks. Contending with these distractions complicates the jobs of the policy maker and the researcher.

This paper avoids these distractions by utilizing a methodology that parallels a "natural experiment" study of twins (Griliches 1979). This methodology focused controls for differences in state-level market conditions, such as cyclical disparities. Our research analyzes those states and regions within the United States that neighbor each other, have similar industrial compositions, and demonstrate a persistent ordering for unemployment rates. These four pairs of states met our criteria as "twins." In addition, one pair of U.S. regions met these criteria. The four

*Department of Economics, Winthrop University. Two anonymous reviewers provided comments that improved the paper. Any errors are the responsibility of the authors. 
pairs of states are Massachusetts and New Hampshire, Michigan and Indiana, Louisiana and Texas, and West Virginia and Kentucky. The regional pair is the East South Central (ESC) and the West North Central (WNC). In each pair, the area listed first has had a higher unemployment rate since at least 1971 (see Chart 1).

This unique sample of states and regions is analyzed using the seemingly unrelated regression estimation technique for the period 1974-1993. The model highlights differences in state unemployment benefits and the generosity of state welfare systems within each pair. Evidence is provided that these existing state incentives not only influence unemployment, but also in some cases have reversed unemployment rates. In other words, the relative generosity of one state's incentive package is shown to have raised unemployment above that of its neighboring state.

\section{STYLIZED FACTS AND DATA}

Throughout the sample period, the unemployment rate paths within each pair never cross. ${ }^{1}$ The average difference in unemployment rates ranges from 1.3 percentage points between Massachusetts and New Hampshire to 2.6 percentage points between West Virginia and Kentucky. There appears to be some consistency in the short-term movements in each group. For example, Kentucky and West Virginia experience large unemployment rate increases in 1982-83, while Texas and Louisiana encounter significant increases in 1986. Massachusetts and New Hampshire are negatively affected in 1990-91.

The similar industrial composition of the areas within each group may account for the similar short-term movements in their unemployment rates. ${ }^{2}$ Each half of the selected pairs has a comparable industrial make-up to its twin. Massachusetts and New Hampshire have evolved from their manufacturing roots into service oriented economies. In Michigan and Indiana the manufacturing sector represented over 30 percent of the output in 1980. Louisiana and Texas have a much greater percentage of mining than the national average. West Virginia and Kentucky are predominately manufacturing and mining oriented.

Areas with similar industrial make-up will encounter similar demands for labor and thus exhibit similar transitory movements in their unemployment rates. However, neither industrial make-up nor speed of adjustment back to some natural rate can explain the long-term persistent differences in unemployment rates among the pairs in our sample.

Previous studies by Topel (1986), Bartik (1991), and Blanchard and Katz (1992) claim that labor demand shifts are responsible for a majority of the short-term fluctuations in employment levels and unemployment rates. However,

\footnotetext{
${ }^{1}$ Unemployment Rates: when possible, the data on employment and the demographic of the labor force were provided by the U.S. Department of Labor, Geographic Profiles of the Employed and the Unemployed. In some of the states the Geographic Profiles of the Employed and the Unemployed series did not begin untiP1976. In these instances, we used the Manpower Report to the President.

2The U.S. Bureau of Economic Analysis, Regional Economic Information System also supplied Gross State Product by industrial sector.
} 
Sources of Prevailing Differences in Unemployment Rates for Selected Regional Pairs 37

\section{Louisiana - Texas}

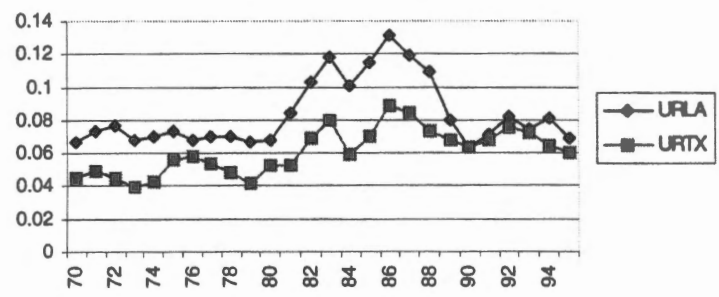

Massachusetts - New Hampshire

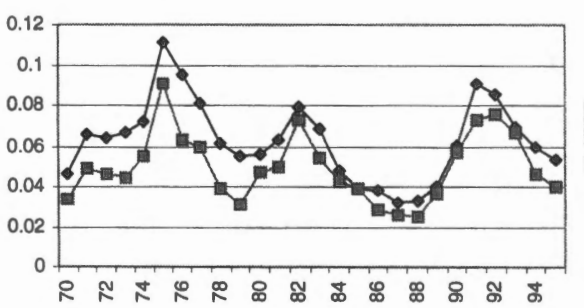

West Virginia - Kentucky

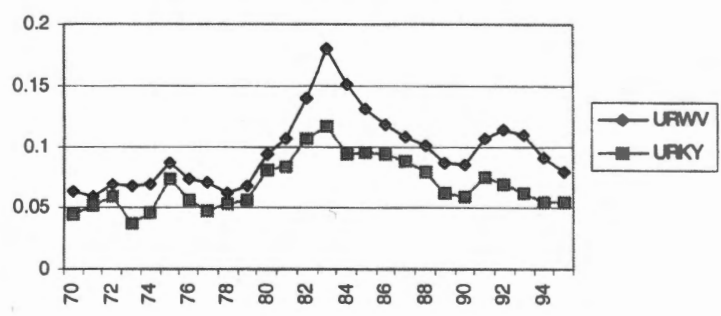

CHART 1

Unemployment

Rates

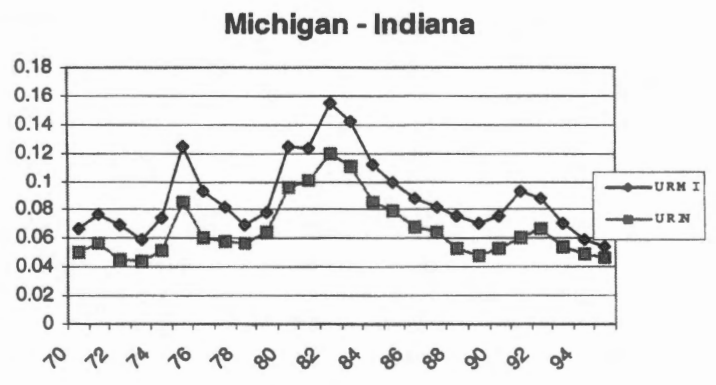

West North Central -

East South Central

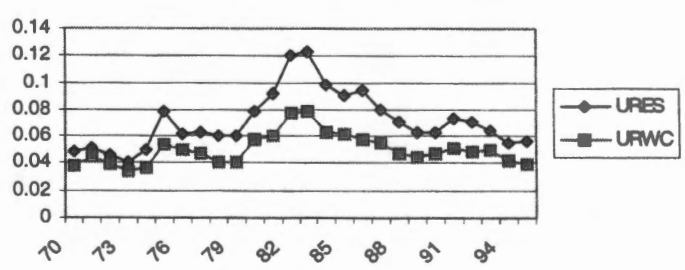


we believe that the evidence signifies that labor supply factors are a primary cause of persistent differences in unemployment rates. Variables that affect the supply of labor include unemployment insurance benefits (Meyer 1990), other government amenities, such as welfare payments (Barro 1988), and unionization of the employed (Summers 1986).

Unemployment insurance increases the reservation wage of the job seeker, allowing more time to search for employment (Marston 1985; Woodbury and Spigelman 1987; Meyer 1990). As search time increases, the duration of unemployment increases. This in turn causes unemployment rates to increase (or remain high). Using an unemployment insurance benefits variable constructed by Keil and Pantuosco (1994), the benefits of each state or region can be compared. The variable BENEFITS consists of two parts: a replacement rate, and the percentage of the unemployed that receive unemployment insurance. ${ }^{3}$ The product of these components provides an estimate of the percentage of wages the typical unemployed worker receives. The higher this percentage, the easier it is to continue searching for employment. In order to focus this measure on the net expected value, the real consumption wage is utilized as the wage measure. Within the context of the benefits variable, the real consumption wage represents the worker's lost wages upon job separation. ${ }^{4} \mathrm{~A}$ three-year moving average is used to control for cyclical fluctuations. With the exception of the ESC and WNC regions, the states with the higher BENEFITS exhibit higher rates of unemployment.

A similar argument can be made for the incentives associated with public assistance programs, such as welfare and Medicaid. These programs typically allow labor force participants to extend their search for employment by supplementing an unemployed worker after unemployment insurance coverage expires (Mofidi and Stone 1990). The variable GENEROSITY measures each state's transfer payments. ${ }^{5}$ As the level of an area's GENEROSITY increases, the area's unemployment rate would also be expected to increase. The area with the higher level of GENEROSITY is also the area with the higher rate of unemployment, except for the case of West Virginia and Kentucky. The GENEROSITY measures for this group cross within the sample period.

${ }^{3}$ Unemployment Insurance Benefits data, which is the product of the replacement rate and the percentage of the unemployed receiving unemployment insurance benefits, was provided by the U.S. Department of Labor, Employment and Training Administration. The specific variables applied were the average weekly wage in covered employment, the average number of weekly-insured unemployed, and the average weekly benefit amount. The average weekly benefit amount divided by the average weekly salary in covered employment is the replacement rate.

"The real consumption wage is one of two components of the wage, the other being the real product wage (see Parkin and Blade 1986; Layard et al. 1991). We assume that the government furnishes the unemployed with many of the benefits formerly provided by the employer, such as medical care and pension. The real consumption wage, which measures the after tax take-home pay of a worker, is derived as wages minus the direct taxes and social security contributions, adjusted for inflation.

5tate Generosity is the percentage of a state's income that is received from Medicare and general welfare funds. Specifically, Medicaid Expenditures, SSI, AFDC, Food Stamps, and Other Welfare Funds were added and then divided by personal income. The U.S. Bureau of Economic Analysis, Regional Economic Information System, supplied the information. 
Areas with high concentrations of unionized workers are argued to experience a higher rate of unemployment than areas with a low concentration of unionized workers (Layard et al. 1991; Summers 1986; Freeman and Medoff 1984). ${ }^{6}$ Workers that are affiliated with unions have relatively more bargaining power than non-union employees. This bargaining power causes the labor supply curve (or wage bargaining equation) to shift to the left. Holding the labor demand constant, wages increase, the number employed decreases, and the unemployment rate increases. ${ }^{7}$ During the sample period, the percent of unionized employees decreased in all areas of our sample. With the exception of the regions within the state groups, the state with the higher percent of unionization also displayed the higher unemployment rate.

Demographic characteristics may also contribute to unemployment rate disparities. To capture demographic differences, four variables have been constructed that adjust unemployment rates for demographic attributes. The age unemployment rate takes the percent of the labor force 16-19 years old and 20 and above and weights each by the respective national unemployment rate. ${ }^{8}$ Using the same technique, the race unemployment rate adjusts for race differences, the industrial unemployment rate adjusts for the industrial make-up, and the educational unemployment rate accounts for the educational attainment level.

Table 1 lists the unemployment rates adjusted for age, race, gender, industrial composition, and the level of educational attainment of the population. There is no evidence to support the claim that demographic characteristics of the labor force can explain the difference in unemployment rates for Massachusetts and New Hampshire. In Table 1 the generated rates are virtually the same. The same is true regarding Michigan and Indiana, and West Virginia and Kentucky. These states clearly behave as twins.

TABLE 1

Demographic Adjusted Unemployment Rates

\begin{tabular}{|c|c|c|c|c|c|c|c|c|c|c|}
\hline & MA & $\mathrm{NH}$ & MI & IN & ES & WC & WV & $\mathrm{KY}$ & LA & TX \\
\hline Edu 80 & .052 & .052 & .055 & .057 & .060 & .054 & .061 & .061 & .059 & .056 \\
\hline Edu 90 & .047 & .046 & .051 & .053 & .057 & .050 & .059 & .058 & .057 & .053 \\
\hline Gender* & .064 & .065 & .064 & .064 & .064 & .065 & .064 & .064 & .064 & .065 \\
\hline Age $^{*}$ & .071 & .071 & .073 & .072 & .071 & .072 & .071 & .071 & .071 & .071 \\
\hline Race* & .059 & .055 & .063 & .061 & .068 & .058 & .058 & .060 & .074 & .063 \\
\hline Industry** & .063 & .066 & .066 & .067 & .067 & .066 & .067 & .068 & .071 & .068 \\
\hline
\end{tabular}

*Averages from 1985 - 1993.

**For the year 1985.

${ }^{6}$ Hirsch and McPherson (1993) provided union data.

If there is a potential for strong efficient bargaining or on-the-demand-curve bargaining, then a vertical or negatively sloped contract curve can occur. The potential for a net gain in employment is then possible. These issues may leave the sign of the UNION variable ambiguous.

${ }^{8} \mathrm{Hence}$, if Michigan has a greater percentage of teenagers in its labor force than Indiana, then the age unemployment rate for Michigan will be higher, explaining some of the unemployment rate disparity between the two states. 
Demographics may play a role in determining variations within the ESC and WNC pair as well as within the Louisiana and Texas pair. The average difference in unemployment rates for the ESC-WNC region is 2.5 percentage points. Table 1 indicates that race unemployment is 1 percentage point higher in the ESC region than in the WNC region. The education unemployment is also higher in the ESC by 0.5 percentage point in the 1980 and 1990 estimates. There is some overlap between the two measures so it would be inaccurate to claim that a 1.5 percentage point difference can be explained by demographic characteristics. However, there is evidence to suggest that at least some of the difference is the result of race and educational differences. ${ }^{9}$

The estimates presented in Table 1 indicate that race unemployment is over 1 percentage point higher in Louisiana than in Texas. Consistent with ESC and WSC, the educational unemployment rate for Louisiana is above that of Texas. Since the gap is 2.5 percentage points, this accounts for a portion of the difference.

What can be derived from the analysis is that differences do exist in the labor supply factors within each group. But there is no single factor that explains the variation throughout time and across states. Unemployment insurance, unionization of the employed, and state generosity are higher in most groups but not all groups. Demographic characteristics are only significant in two of the five groups.

If our objective was to develop a cross-sectional sample of state unemployment rates, it would be necessary to incorporate these measures for educational attainment and demographics within the regression estimation. However, due to the pairing of states over time, measures of these control variables would not display adequate variability between the counterparts. Some of the unexplained variability from our approach may be attributed to hysteresis associated with long-term differences in demographics or educational systems. These differences could conceivably predate the sample and still be providing some lingering influence.

\section{METHODOLOGY}

The literature discussed in the previous section suggests a model of unemployment where labor supply can be influenced at the state level by state unemployment benefits and the generosity of a state's public assistance. This poses an empirical question. Which states have persistent unemployment that can be linked to structural differences in the state benefit package?

The nature of the question suggests that Zellner's (1962) seemingly unrelated regression (SURE) technique is an appropriate estimation procedure. The different equations representing the impact of unemployment differences would be influenced by common underlying factors in the economy. This phenomenon of contemporaneous autocovariance of disturbances implies that ${ }^{9}$ Educational Attainment was obtained from the U.S. Statistical Abstracts for census years. 
separate Ordinary Least Squares Regressions would be inefficient, and Zellner's SURE technique would yield an efficient estimator.

The equation to be estimated is:

$$
\mathrm{UNEMP}=\beta_{0}+\beta_{1} \text { BENEFITS }+\beta_{2} \text { GENEROSITY }+\beta_{3} Z
$$

where $\mathrm{Z}$ is a vector containing various control factors expressed as differences. These include the change in Gross State Product, GSP, the difference in the measure of unionism, UNION, and the lagged measure of the dependent variable, LAG. The lagged variable is included due to the expected presence of autocorrelation in the time series data. For a discussion of autocorrelation with lagged dependent variables see Durbin (1970).

To investigate this question using the sample of neighboring states and geographic regions, the measures of unemployment rates, UNEMP, unemployment insurance benefits, BENEFITS, and public assistance, GENEROSITY, were all included as the difference between the counterpart measures.

\section{RESULTS}

Table 2 summarizes the results from estimating Equation (1) using the SURE technique with common coefficients for the independent variables. A separate intercept term is estimated for each group.

TABLE 2

Regression Coefficients

(Absolute value of the $t$-statistic in parentheses)

\begin{tabular}{|c|c|c|c|c|c|}
\hline \multicolumn{6}{|c|}{ Unemployment Rate } \\
\hline Intercept & $\begin{array}{l}\text { MA-NH } \\
-0.0078 \\
(1.54)\end{array}$ & $\begin{array}{l}\text { MI-IN } \\
-0.0029 \\
(0.82)\end{array}$ & $\begin{array}{l}\text { WV-KY } \\
0.0090^{*} \\
(2.96)\end{array}$ & $\begin{array}{l}\text { LA-TX } \\
-0.0029 \\
(0.62)\end{array}$ & $\begin{array}{l}\text { ES-WC } \\
0.0166^{* *} \\
(2.20)\end{array}$ \\
\hline LAG & $\begin{array}{l}0.681^{*} \\
(9.64)\end{array}$ & & & & \\
\hline BENEFITS & $\begin{array}{l}0.0087^{* *} \\
(2.5)\end{array}$ & & & & \\
\hline GENEROSITY & $\begin{array}{l}0.2188 \\
(1.50)\end{array}$ & & & & \\
\hline GSP & $\begin{array}{l}-0.0463^{* * *} \\
(1.90)\end{array}$ & & & & \\
\hline UNION & $\begin{array}{l}0.0024 \\
(1.07)\end{array}$ & & & & \\
\hline $\mathbf{R}^{2}$ & .21 & .15 & .50 & .68 & .55 \\
\hline Durbin-Watson & 2.15 & 1.97 & 1.39 & 1.31 & 1.72 \\
\hline
\end{tabular}

$\mathrm{N}=100$

Significance

$* 99 \%(>2.576)$

**95\% (>1.960)

$* *$ * $90 \%(>1.645)$ 
Both BENEFITS and GENEROSITY have the expected sign in the regression. However, only the variable BENEFITS is significant. GSP is negative and significant. This implies that the difference in unemployment rates is countercyclical. When the economy expands, the difference in unemployment rates falls. Conversely, a recession will increase unemployment rate differences. This poses a structural question. For economic regions, in general, is it expected that economic growth will always reduce unemployment rate differences? What causes some areas to consistently suffer from an exaggerated sensitivity to unemployment cycles?

Estimation with common coefficients appears too restrictive to shed light on the state specific factors that drive unemployment rate differences. Table 3 presents a reestimation of the equation with separate coefficients estimated for each state. This estimation reveals the extent to which this model captures structural changes for a particular pair of states. The SURE technique is utilized, not because these structural differences are expected to be the same across states, but rather because different structural relationships are influenced by common contemporaneous covariance. Consider the results on a case-by-case basis.

TABLE 3

Regression Coefficients

(Absolute value of the $t$-statistic in parentheses)

\begin{tabular}{lccccc}
\hline \multicolumn{5}{c}{ Unemployment } \\
Intercept & MA-NH & MI-IN & WV-KY & LA-TX & ES-WC \\
& -0.0068 & $-0.027^{*}$ & $0.02^{* * *}$ & $-0.029^{* *}$ & $0.011^{* *}$ \\
LAG & $(.70)$ & $(2.87)$ & $(1.92)$ & $(2.42)$ & $(2.42)$ \\
& 0.168 & $0.65^{*}$ & $0.77^{*}$ & $0.56^{*}$ & $0.60^{*}$ \\
BENEFITS & $(.89)$ & $(3.1)$ & $(6.47)$ & $(4.36)$ & $(3.85)$ \\
& -0.0036 & $0.043^{* *}$ & $0.027^{* *}$ & $0.04^{*}$ & 0.022 \\
GENEROSITY & $(.80)$ & $(2.47)$ & $(2.39)$ & $(3.29)$ & $(.22)$ \\
& 0.58 & $1.77^{*}$ & 0.577 & $0.86^{* *}$ & 0.29 \\
GSP & $(1.55)$ & $(4.47)$ & $(1.00)$ & $(2.54)$ & $(.94)$ \\
& $-0.27^{*}$ & $-0.182^{* *}$ & -0.09 & -0.095 & -0.03 \\
UNION & $(3.77)$ & $(2.55)$ & $(1.5)$ & $(1.29)$ & $(.74)$ \\
& 0.0048 & $0.048^{* *}$ & 0.003 & 0.004 & 0.047 \\
$\mathrm{R}^{2}$ & $(.43)$ & $(2.30)$ & $(1.25)$ & $(.3)$ & $(1.22)$ \\
Durbin-Watson & .57 & .45 & .50 & .74 & .61 \\
F- Statistic & 2.21 & 1.96 & 1.40 & 1.55 & 1.90 \\
\hline
\end{tabular}

$\mathrm{N}=100$

Significance

*99\% (>2.576)

$* * 95 \%(>1.960)$

$* * * 90 \%(>1.645)$

\section{MICHIGAN-INDIANA}

The unemployment rate differences between Michigan and Indiana are the most responsive to the model posed. Each variable is significant with the expected sign. Both BENEFITS and GENEROSITY coefficients reveal a strong significant relationship between the payouts of these programs and the difference in the 
unemployment rates in these states. The control variables for GSP and UNION also significantly influenced the unemployment rate difference. When the underlying industrial structure of these states is considered it is not surprising that these variables would capture some important dynamics. The influence of the cyclical Michigan auto industry is confirmed through these variables. The movements in GSP are linked in a countercyclical pattern with unemployment differences. When the economy expands, unemployment differences between Michigan and Indiana narrow. During an economic downturn, the unemployment gap widens.

Unionization has a direct impact on unemployment. When union membership increases, so does unemployment. This result should not be interpreted as indicating that union employees are more likely to suffer layoffs. Rather, it could be indicative of a positive impact from union bargaining on efficiency wages. ${ }^{10}$

Another interesting result from the Michigan and Indiana data is the negative significant intercept term. This would imply that the impact of the explanatory variables has in fact reversed the underlying dynamics for unemployment differences. In other words, the incentive structure in Michigan has raised the unemployment rate above that in Indiana.

As a policy implication, this means that a reduction in BENEFITS and GENEROSITY in Michigan has the potential to reverse the persistent unemployment gap with the neighboring state of Indiana. However, an important question is "Should the Unemployment Rate be lowered?" Search is a process that the state of Michigan has chosen to subsidize to a greater degree than its twin Indiana. Although policy reform will influence the underlying rates of unemployment, this type of analysis does not indicate whether either Michigan or Indiana has achieved its preferred search equilibrium.

\section{LOUISIANA-TEXAS}

The results of the estimation for Louisiana and Texas are also interesting. Here we do not have the significant impact found through unionization and cyclical industry as in Michigan. Consequently, the control variables of UNION and GSP are not significant although they carry the expected sign. The influence of BENEFITS and GENEROSITY again are significant and impact the unemployment rates in the direction anticipated. It is interesting to note that the magnitude of the GENEROSITY variable is markedly different between these states than that seen in the Midwestern comparison of Michigan and Indiana. This could reflect underlying structural differences in the design of the programs in these states. Again, the intercept term suggests that the policy structure of BENEFITS and GENEROSITY has in fact reversed the unemployment rate difference between these states.

${ }^{10}$ There is a potential for multicollinearity between the cyclical dynamics of GSP and unionization. However, the dynamics of the union variable do appear to capture a distinct variation in unemployment consistent with the efficiency wage model (Shapiro and Stiglitz 1984). 


\section{WEST VIRGINIA-KENTUCKY}

The estimation model posed does not provide significant explanatory evidence for the gap in unemployment rates between West Virginia and Kentucky. The only significant variables were the lag term and BENEFITS. This suggests that the unemployment rate gap reflects persistent structural differences between these states that have been in place throughout the time period estimated. The explanatory variables reflect the expected direction of impact but not all were significant.

\section{MASSACHUSETTS-NEW HAMPSHIRE}

In the final comparison between Massachusetts and New Hampshire, the underlying model again did not capture the structural differences in the labor market between the two states. The direction of each coefficient was as expected, but the only significant influence was the cyclical impact of GSP. Changes in the national growth rate do have a significant countercyclical impact on unemployment rate differences in these states. Here again, the unemployment rate difference declines during periods of economic expansion and the difference grows during economic downturn.

\section{REGIONAL RESULTS}

Within the seemingly unrelated estimation structure, evidence was also gathered for one pair of regions with a persistent unemployment gap. It is interesting to include the regional data since one would expect that this level of aggregation would also be exposed to the same contemporaneous shocks seen by the various states. The results from Table 3 reveal that only the intercept and lag terms are significant for the regional equation. This type of result is consistent with the nature of aggregated data. By aggregating across states within a region, the influence of structural differences within the package of BENEFITS and GENEROSITY can no longer be significantly identified. This type of result would be expected if there is variation between states within the regions in addition to that between states of different regions. The failure of the regional data emphasizes the importance of using state-level data to capture structural differences in unemployment.

\section{CONCLUSION}

This paper provides a focused examination of state fiscal policies on labor supply. To compare unemployment rates, four U.S. states and one U.S. region were matched with neighboring twins that exhibit similar labor demand relationships. In each case, a difference in unemployment rates has persisted since the early 1970s. The impact of state fiscal policies on unemployment insurance and public assistance on the differences in unemployment rates is estimated. Both fiscal packages contribute to the unemployment difference for some states.

The evidence suggests that both Michigan and Louisiana have unemployment rates higher than their counterparts (Indiana and Texas, respectively) 
through the influence of these fiscal policies. This result suggests that state experiments in welfare reform have the potential to reverse longstanding orderings of relative unemployment rates. The realization would depend upon policy choices to be made in each state. To the extent that the ordering of unemployment reflects the desired subsidization of the search process, each pair of states may choose policies of reform that preserve the current ordering. However, should the current subsidization of search unemployment be considered excessive, then policy reform has the opportunity to reduce unemployment and ease labor market distortions.

Control variables capturing the impact of unionization, persistence, and fluctuations in GSP all were shown to have influence in some state differences. Perhaps the most interesting issue raised by these control variables is the suggestion that unemployment rate differences are in fact countercyclical. An expanding economy does cause unemployment rates to converge.

\section{REFERENCES}

Barro, Robert J. "The Persistence of Unemployment." American Economic Review, Papers and Proceedings 78 (1988): 32-37.

Bartik, T.J. Who Benefits From State and Local Economic Development Policies? Kalamazoo, MI: W.E. Upjohn Institute for Employment Research, 1991.

Blanchard, Oliver J. and L.F. Katz. "Regional Evolutions." Brookings Papers on Economic Activity 1 (1992): 1-61.

Durbin, J. "Testing for Serial Correlation in Least Squares Regression When Some of the Regressors are Lagged Dependent Variables." Econometrica 38 (1970): 410-21.

Freeman, R.B. and J.L. Medoff. What Do Unions Do? New York: Basic Books, 1984. Griliches, Zvi. "Sibling Models and Data in Economics: Beginnings of a Survey." Journal of Political Economy 87 (1979): S37-S64.

Hirsch Barry T. and David A. Macpherson. "Union Membership and Coverage files from the Current Population Surveys: Note." Industrial and Labor Relations Review 46 (1993).

Keil, M.W. and L.J. Pantuosco. "Variation in State Unemployment Rates: A Com parative Macroeconomic Performance Analysis." The Southern Business and Economics Journal 17 (1994): 114-136.

Layard, Richard, S. Nickell and R. Jackman. Unemployment: Macroeconomic Performance and the Labour Market. Oxford: Oxford University Press, 1991.

Marston, Stephen T. "Two Views of the Geographic Distribution of Unemployment." The Quarterly Journal of Economics 100 (1985): 57-79.

Meyer, Bruce D. "Unemployment Insurance and Unemployment Spells." Econometrica 58 (1990): 757-782.

Mofidi, Alaeddin and Joe A. Stone. "Do State and Local Affect Economic Growth?" The Review of Economics and Statistics, 72 (1990): 686-691. 
Parkin, Michael and R. Blade. Modern Macroeconomics. Scarborough, Ontario: Prentice-Hall Canada Inc., 1986.

Shapiro, Carl and Joseph E. Stiglitz. "Equilibrium Unemployment as a Worker Discipline Device." American Economic Review 73 (1984): 433-444.

Summers, L. "Why is the Unemployment Rate So Very High Near Full Employment?" Brookings Papers on Economic Activity 2 (1986): 339-383.

Topel, Robert H. "Local Labor Markets." Journal of Political Economy 94 (1986): S111-43.

U.S. Department of Labor. Geographic Profiles of the Employed and the Unemployed, 1974-1993.

Woodbury, Steven A. and Robert G. Spiegelman. "Bonuses to Workers and Employers to Reduce Unemployment: Randomized Trails in Illinois." American Economic Review 77 (1987): 513-530.

Zellner, A. "An Efficient Method of Estimating Seemingly Unrelated Regressions and Tests for Aggregation Bias." Journal of the American Statistical Association 57 (1962): 348-368. 